\title{
Electrodeposition of Ferromagnetic Metal Nanowires
}

\author{
Takeshi Ohgai ${ }^{1}$, Keizo Takao $^{1}$, Masayuki Mizumoto $^{1}$, Akio Kagawa $^{1}$, \\ Yoshitomo Tanaka² and Shigekazu Sumita ${ }^{2}$
}

1. Department of Materials Science and Eng., Faculty of Engineering, Nagasaki University, 1-14 Bunkyo-machi, Nagasaki, 852-8521, Japan

2. TDK Corporation, 2-15-7 Higashi-Ohwada, Ichikawa-shi, Chiba, 272-8558, Japan

Email: ohgai@nagasaki-u.ac.jp

Keywords: Electrodeposition, Ferromagnetic, Nanowire, Nanochannel, Membrane

\begin{abstract}
Ni-Fe alloy films and nanowires were fabricated using electrodeposition technique. The cylindrical shape of nanowires was precisely transferred from the nanochannels of membrane filters and the aspect ratio reached to around 60. Coercive force in in-plan direction of Ni-Fe alloy films decreased to ca. 1 Oe with increasing Fe content in deposits while, in perpendicular direction, the films were hardly magnetized. Magnetic hysteresis loops revealed that the nanowires were spontaneously magnetized to the long axis direction and the coercive force reached to ca. 200 Oe.
\end{abstract}

\section{Introduction}

The array of numerous metallic nanowires with straight shape has much attention due to their shape anisotropy and extremely large surface area. Metallic nanowires can be fabricated by manipulating metallic atoms one by one using scanning tunneling microscopy (STM), while they can be also prepared by electrochemically depositing metallic atoms into a nano-well template with numerous nanochannels [1-6]. Nano-well templates such as anodized aluminum oxide films with high density of nanochannels (about $10^{8} \sim 10^{10} \mathrm{~cm}^{-2}$ ) have been used so far in template synthesis technique [7-9]. In the template synthesis technique using fabrication of nanochannels and electrodeposition of nanowires, position of each nanochannels, inter-channel distance, channel diameter and channel shape should be controlled precisely [10-12]. Lithographic galvanoforming (LIGA) process using laser, UV, X-ray, electrons and ions is most promised technique to obtain the wide range order of nanochannels and nanowires. Especially, ferromagnetic metal nanowires array is the best candidate to be applied for magnetic storage media with high density domain.

In this study, Iron-group metals such as $\mathrm{Ni}$ and $\mathrm{Ni}-\mathrm{Fe}$ alloy were potentio-statically electrodeposited into ion-track etched polycarbonate membrane filters with numerical cylindrical nanochannels to synthesize the ferromagnetic metal nanowires array.

\section{Experimental}

Ion track-etched polycarbonate membrane filters with pore-diameter of $100 \mathrm{~nm}$, pore-length of $6000 \mathrm{~nm}$ and pore-density of $10^{8}$ pore $\mathrm{cm}^{-2}$ were used as a template for growing metallic nanowires while copper foils were used as a cathode for electrodepositing metallic films. On a surface of the membrane filter, a gold layer was sputter-deposited to cover the pores and make a cathode. Aqueous solution containing metal sulfate was used as electrolyte. The solution compositions are shown in Table 1 . To determine the optimum deposition potential for growing nanowires, cathodic polarizarion behavior was investigated in a wide range of cathode potential. $\mathrm{Ni}$ and $\mathrm{Ni}-\mathrm{Fe}$ alloy nanowires were potentio-statically electrodeposited at $313 \mathrm{~K}$. To investigate the relationship between $\mathrm{Fe}^{2+}$ concentration ratio $\left(R^{\mathrm{Fe} / \text { bath }}=\left[\mathrm{Fe}^{2+}\right] /\left(\left[\mathrm{Fe}^{2+}\right]+\left[\mathrm{Ni}^{2+}\right]\right)\right)$ in baths and $\mathrm{Fe}$ content $\left(R^{\text {Fe/depo }}\right.$ $=[\mathrm{Fe}] /([\mathrm{Fe}]+[\mathrm{Ni}]))$ in Ni-Fe alloy deposits, the composition of electrodeposits were determined using EDX analysis. After the growing nanowires, polycarbonate membrane filters were dissolved in 
organic solvent and the remains consisted of nanowires and a gold layer was served as a sample for SEM observation. Magnetic hysteresis loops of electrodeposited films and nanowires were obtained using vibrating sample magnetometer (VSM) with increasing the magnetic field up to $10 \mathrm{kOe}$.

Table 1 Electrolytic solution composition for electrodeposition of Ni-Fe alloys.

\begin{tabular}{|c|c|c|c|c|}
\hline & $\begin{array}{c}\mathrm{NISO}_{4} \cdot 7 \mathrm{H}_{2} \mathrm{O} \\
(\mathrm{mol} / \mathrm{L})\end{array}$ & $\begin{array}{c}\mathrm{FeSO}_{4} \cdot 7 \mathrm{H}_{2} \mathrm{O} \\
(\mathrm{mol} / \mathrm{L})\end{array}$ & $\begin{array}{l}\mathrm{H}_{3} \mathrm{BO}_{3} \\
(\mathrm{~mol} / \mathrm{L}) \\
\end{array}$ & $\begin{array}{c}{\left[\mathrm{F} \theta^{2+}\right] /\left(\left[\mathrm{F} \theta^{2+}\right]+\left[\mathrm{N}^{2+}\right]\right)} \\
(\mathrm{K})\end{array}$ \\
\hline (1) & 0.4950 & 0.0050 & 0.75 & 1.0 \\
\hline (2) & 0.4925 & 0.0075 & 0.75 & 1.5 \\
\hline (3) & 0.4900 & 0.0100 & 0.75 & 2.0 \\
\hline (4) & 0.4850 & 0.0150 & 0.75 & 3.0 \\
\hline (5) & 0.4350 & 0.0650 & 0.75 & 13.0 \\
\hline
\end{tabular}

\section{Results and Discussions}

\section{Ni-Fe alloy films}

Figure 1 shows cathodic polarization curves for the electrodeposition of $\mathrm{Ni}$ and Ni-Fe alloy. For the Ni-Fe alloy deposition, the solutions containing $1.5 \%$ of $\mathrm{Fe}^{2+}$ ions concentration ratio $\left(R^{\text {Fe/bath }}=1.5 \%\right)$ was used as shown in Table 1-(2). The cathodic current begins to occur at ca. $0 \mathrm{~V}$ vs.Ag/AgCl, which is more-noble than the equilibrium potential of $\mathrm{Ni}$ and Fe. Therefore, this cathodic current is presumed to be reduction current of $\mathrm{H}^{+}$ions. With increasing the cathodic current, at around $10^{-3} \mathrm{~A}$, the potential polarizes to be around $-0.7 \mathrm{~V}$ due to the diffusion limit of $\mathrm{H}^{+}$ions. At around $-0.7 \mathrm{~V}$, the cathodic current for Ni deposition increases again, while the cathodic current for $\mathrm{Ni}$-Fe alloy deposition increases at around $-0.8 \mathrm{~V}$. This increase in cathodic current is mainly caused by an increase in deposition current of $\mathrm{Ni}$ and $\mathrm{Ni}-\mathrm{Fe}$ [13-15]. At the potential region less than $-1.2 \mathrm{~V}$, with increasing cathodic current, the potential polarizes significantly to be less-noble region due to the diffusion limit of $\mathrm{Ni}^{2+}$ and $\mathrm{Fe}^{2+}$ ions. Consequently, the optimum cathode potential for electrodeposition of $\mathrm{Ni}$ and $\mathrm{Ni}-\mathrm{Fe}$ alloys is determined to be $-1.0 \mathrm{~V}$.

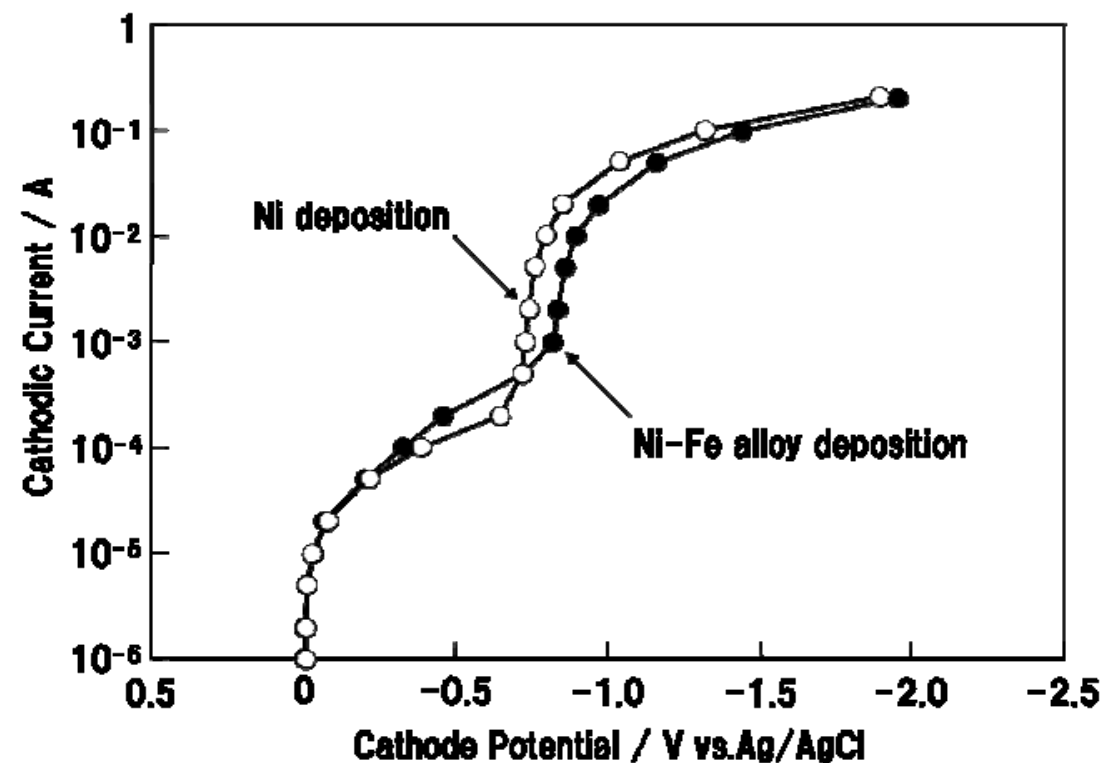

Figure 1 Cathodic polarization curves for the electrodeposition of $\mathrm{Ni}$ and $\mathrm{Ni}-\mathrm{Fe}$ alloy from aqueous solutions containing $\mathrm{Ni}^{2+}$ and $\mathrm{Fe}^{2+}$ ions. 
Figure 2 shows the relationship between $\mathrm{Fe}^{2+}$ concentration ratio $\left(R^{\mathrm{Fe} / \mathrm{bath}}\right)$ in baths and Fe content $\left(R^{F e / d e p o}\right)$ in Ni-Fe alloy deposits. With increase in $R^{\text {Fe/bath }}, R^{\text {Fe/depo }}$ also increases. In the figure, composition reference line (C.R.L) means $R^{\text {Fe/depo }}$ corresponds to $R^{\text {Fe/bath }}$. In this study, less-noble Fe preferentially electrodeposited rather than Ni. For example, Ni-22at.\%Fe alloy deposit $\left(R^{F e / d e p o}=22 \%\right)$ was obtained from the solution containing $1.5 \%$ of $\mathrm{Fe}^{2+}$ ions $\left(R^{\text {Fe/bath }}=1.5 \%\right)$. Fe ratio in deposit was condensed ca. 10 times higher than $\mathrm{Fe}^{2+}$ ratio in bath. This result can be explained by the anomalous codeposition mechanism due to the formation and adhesion of $\mathrm{Fe}(\mathrm{OH})_{2}$ on cathode [13-15].

Figure 3 shows the magnetic hysteresis loops of $\mathrm{Ni}$ film and $\mathrm{Ni}-22 \mathrm{at} . \% \mathrm{Fe}$ alloy film electrodeposited on a copper foil. Magnetic field was applied to in-plan direction (//) and perpendicular direction $(\perp)$ to the film plan. As shown in these figures, in perpendicular direction, the films were hardly magnetized. On the other hand, in-plan direction, the films were easily magnetized and the magnetization reached to saturation at less than $1 \mathrm{kOe}$. Coercive force of Ni-22at.Fe alloy film was ca. 1 Oe, which is quite smaller than that of Ni film (ca. $110 \mathrm{Oe}$ ). This is resulting from decreasing the magnetic anisotropy constant and magnetostriction constant of Ni with increase in Fe content in Ni-Fe alloy.

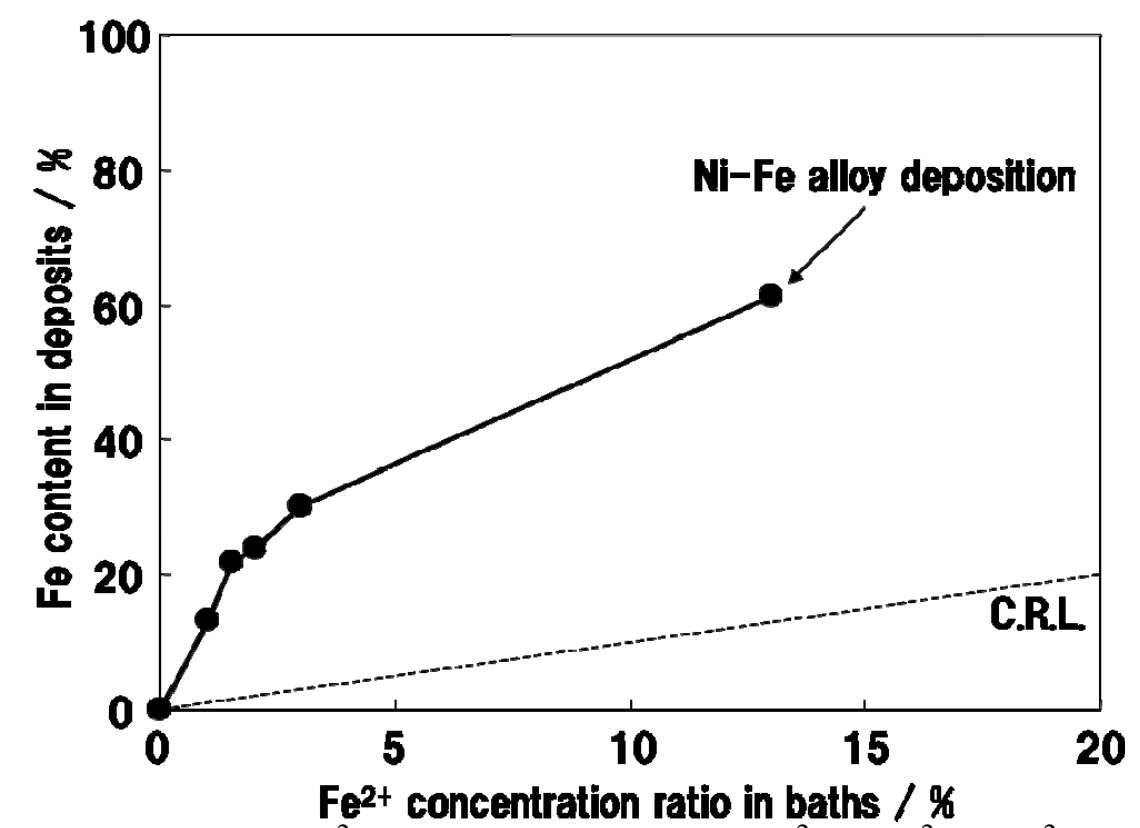

Figure 2 Relationship between $\mathrm{Fe}^{2+}$ concentration ratio $\left(\left[\mathrm{Fe}^{2+}\right] /\left(\left[\mathrm{Fe}^{2+}\right]+\left[\mathrm{Ni}^{2+}\right]\right)\right)$ in baths and $\mathrm{Fe}$ content in Ni-Fe alloy deposits.

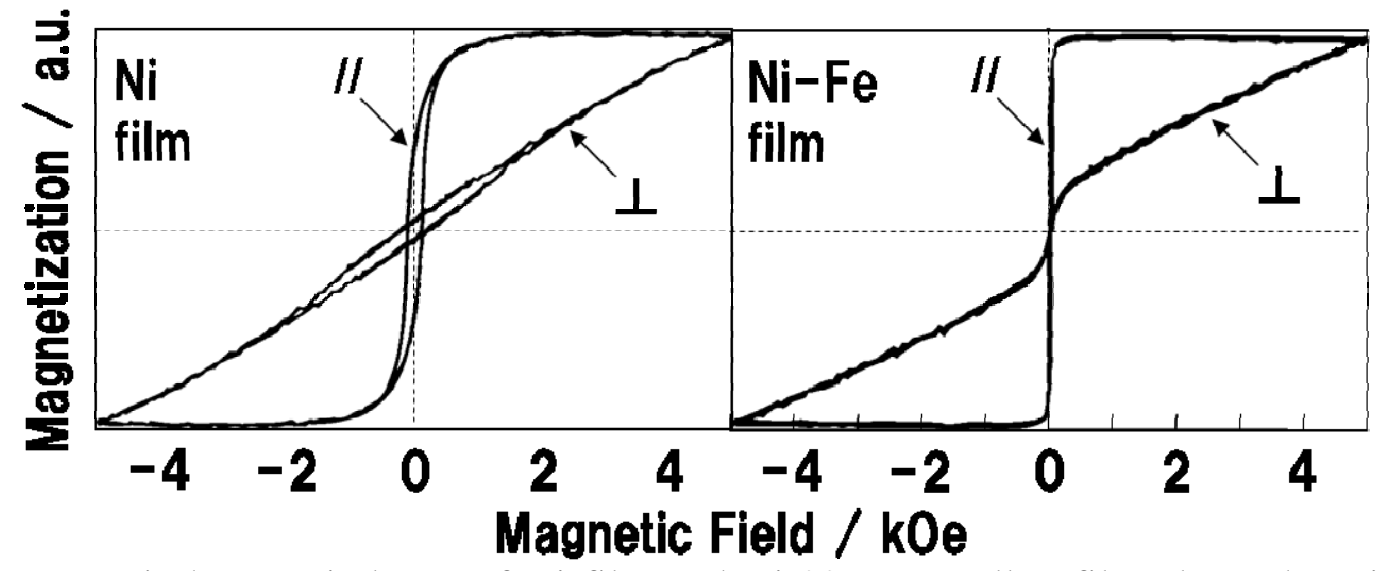

Figure 3 Magnetic hysteresis loops of Ni film and Ni-22at.\%Fe alloy film electrodeposited from aqueous solutions. 
Figure 4 shows the relationship between Fe content in Ni-Fe alloy deposits $\left(R^{F e / d e p o}\right)$ and the coercive force obtained from magnetic hysteresis loops with the applied magnetic field of in-plan direction (//). With increase in Fe content in deposits, the coercive force decreased down to ca. several Oe level. It is well known that coercive force, $\mathrm{H}_{\mathrm{c}}$ is expressed by the following equation if the rotation process is dominant in magnetization. $\mathrm{H}_{\mathrm{c}}=2 \mathrm{~K} / \mathrm{M}_{\mathrm{s}}$. Here, $\mathrm{K}$ and $\mathrm{M}_{\mathrm{s}}$ mean magnetic anisotropy constant and saturated magnetization. Magnetic anisotropy constants of $\mathrm{Ni}$ and $\mathrm{Fe}$ are followings. $\mathrm{K}_{\mathrm{Ni}}=-4.5 \mathrm{~kJ} / \mathrm{m}^{3}(-562.5 \mathrm{kGOe})$ and $\mathrm{K}_{\mathrm{Fe}}=+48 \mathrm{~kJ} / \mathrm{m}^{3}$ (+6000 kGOe). Saturated magnetization of $\mathrm{Ni}$ and $\mathrm{Fe}$ are followings. $\mathrm{M}_{\mathrm{Ni}}=0.61 \mathrm{~T}(6100 \mathrm{G})$ and $\mathrm{M}_{\mathrm{Fe}}=2.16 \mathrm{~T}(21600 \mathrm{G})$. Therefore, the theoretical coercive force of $\mathrm{Ni}, \mathrm{H}_{\mathrm{Ni}}$ is estimated to be around $184 \mathrm{Oe}$, which is larger than the value (ca. 110 Oe) obtained in this study. If the magnetic anisotropy constant and saturated magnetization of Ni-Fe alloy can be expressed by the following equation, $\mathrm{K}_{\mathrm{Ni}-\mathrm{Fe}}=\mathrm{K}_{\mathrm{Ni}} \times\left(1-R^{\text {Fe/depo }}\right)+$ $\mathrm{K}_{\mathrm{Fe}} \times R^{\text {Fe/depo }}, \mathrm{M}_{\mathrm{Ni}-\mathrm{Fe}}=\mathrm{M}_{\mathrm{Ni}} \times\left(1-R^{\text {Fe/depo }}\right)+\mathrm{M}_{\mathrm{Fe}} \times R^{\text {Fe/depo }}$, the theoretical coercive force of Ni-Fe alloy, $\mathrm{H}_{\mathrm{Ni}-\mathrm{Fe}}$ will be expressed by the following equation, $\mathrm{H}_{\mathrm{Ni}-\mathrm{Fe}}=2 \mathrm{~K}_{\mathrm{Ni}-\mathrm{Fe}} / \mathrm{M}_{\mathrm{Ni}-\mathrm{Fe}}$. In this theory, Ni-9at.\%Fe alloy will show minimum coercive force, which is almost zero. On the other hand, if the domain wall process is dominant in magnetization, $H_{c}$ is expressed by the following equation. $H_{c} \infty \lambda \sigma / M_{s}$. Magnetostriction constant of $\mathrm{Ni}$ and Fe are followings. $\lambda_{\mathrm{Ni}}=-2.0 \times 10^{-5}$ and $\lambda_{\mathrm{Fe}}=+2.0 \times 10^{-5}$. In this theory, Ni-50at.\%Fe alloy will show minimum coercive force, which is almost zero. In this study, as shown in Figure 4, the Ni-Fe alloy films with low coercive force were obtained over the wide range of Fe content from $20 \%$ to $60 \%$.

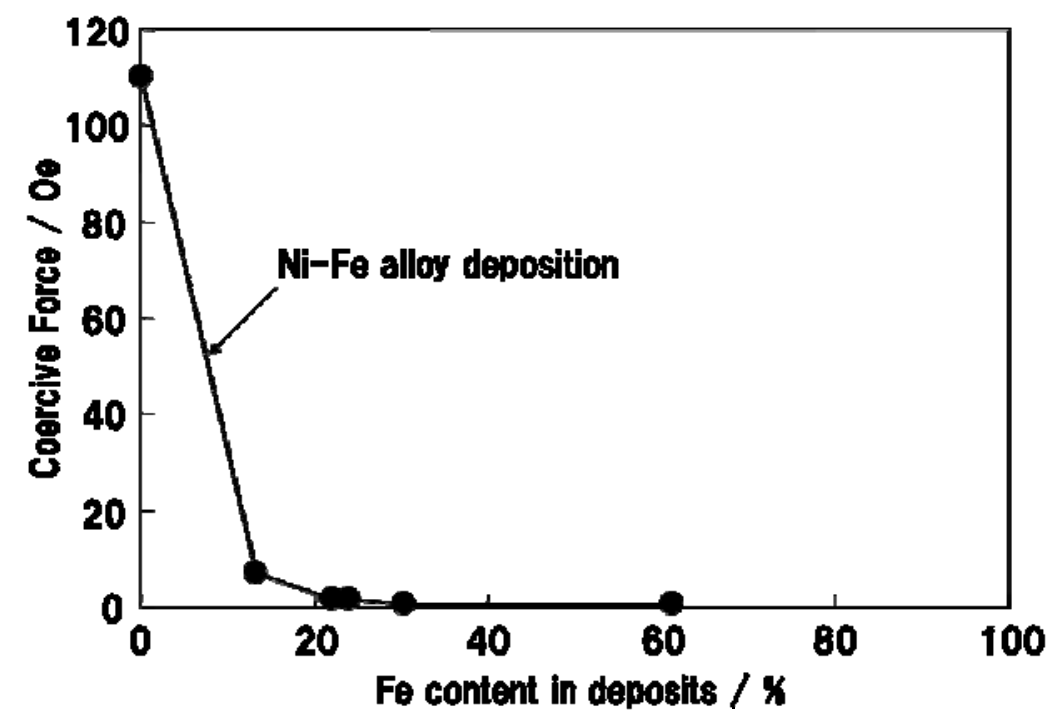

Figure 4 Relationship between Fe content in Ni-Fe alloy deposits and the coercive force obtained from magnetic hysteresis loops of the alloy.

\section{Ni-Fe alloy nanowires}

To investigate the growing process of nanowires, time-dependence of cathodic current was monitored. During the electrodepostion of $\mathrm{Ni}$ and Ni-Fe alloys, the cathode potential was fixed to $-1.0 \mathrm{~V}$. At the beginning of electrolysis within several tens minutes, the cathodic current reached up to ca. $1 \mathrm{~mA}$. Then, the current rapidly decresed to be ca. $0.4 \mathrm{~mA}$ and kept the magnitude until around 1000 sec. During this process, electrodeposition of Ni and Ni-Fe alloys proceed in the nanochannels. At the initial stages of the electrodepostion, large cathodic current was observed. The concentration of metal ions in the nanochannels will decrease with increasing electrodeposition time due to the cathodic reduction, while the metal ions will be provided from the bulk solution to the nanochannels, where the metal ions are consumed by the electrodeposition. Finally, the cathodic current rapidly increases at the deposition time more than 1000 sec. At this stage, electrodeposited nanowires reach the surface of the membranes and large hemispheric Ni and Ni-Fe alloy deposits are formed. Growth 
rate of $\mathrm{Ni}$ and $\mathrm{Ni}-\mathrm{Fe}$ alloy nanowires can be estimated as ca. $6 \mathrm{~nm} \bullet \mathrm{sec}^{-1}$ at the cathode potential of $-1.0 \mathrm{~V}$.

Figure 5 shows SEM image of Ni-22at.\%Fe alloy nanowires separated from polycarbonate template. Diameter and length of the nanowires corresponds well to that of nanochannels and the cylindrical shape was precisely transferred from the nanochannels to the nanowires. Aspect ratio of the nanowires reaches up to around 60. TEM bright images and diffraction patterns of electrodeposited $\mathrm{Ni}$ and Fe nanowires were also investigated. According to TEM bright images, cross-sectional area of the nanowire was almost to be round shape, while the diffraction patterns are composed of spots, which means a nanowire consists of a single crystal domain.

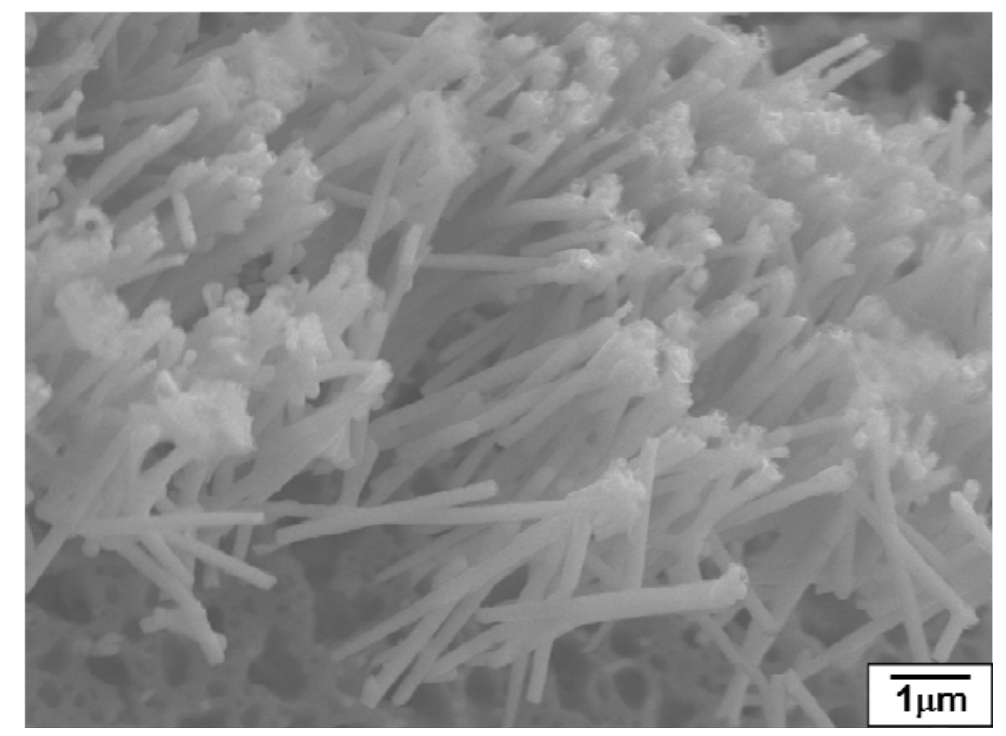

Figure 5 SEM image of electrodeposited Ni-22at.\%Fe alloy nanowires separated from polycarbonate membrane filter.

Figure 6 shows the magnetic hysteresis loops of $\mathrm{Ni}$ and $\mathrm{Ni}-22 \mathrm{at} . \% \mathrm{Fe}$ alloy nanowires electrodeposited into polycarbonate templates with pore-diameter of $100 \mathrm{~nm}$. Magnetic field was applied to in-plan direction $(/ /)$ and perpendicular direction $(\perp)$ to the membrane film plan. The perpendicular direction to the membrane film plan corresponds to the parallel direction to the long axis of nanowires. As shown in these figures, in-plan direction, the nanowires were hardly magnetized. On the other hand, in perpendicular direction, the nanowires were easily magnetized and the magnetization reached to saturation at less than $1 \mathrm{kOe}$. Coercive force of Ni-22at.Fe alloy nanowires was ca. 200 Oe, which is almost same value to the Ni nanowires (ca. $200 \mathrm{Oe}$ ) and the magnetic hysteresis loops show typical perpendicular magnetization behavior. This is resulting from the uni-axial magnetic anisotropy and single magnetic domain structure of the nanowires with large aspect ratio.

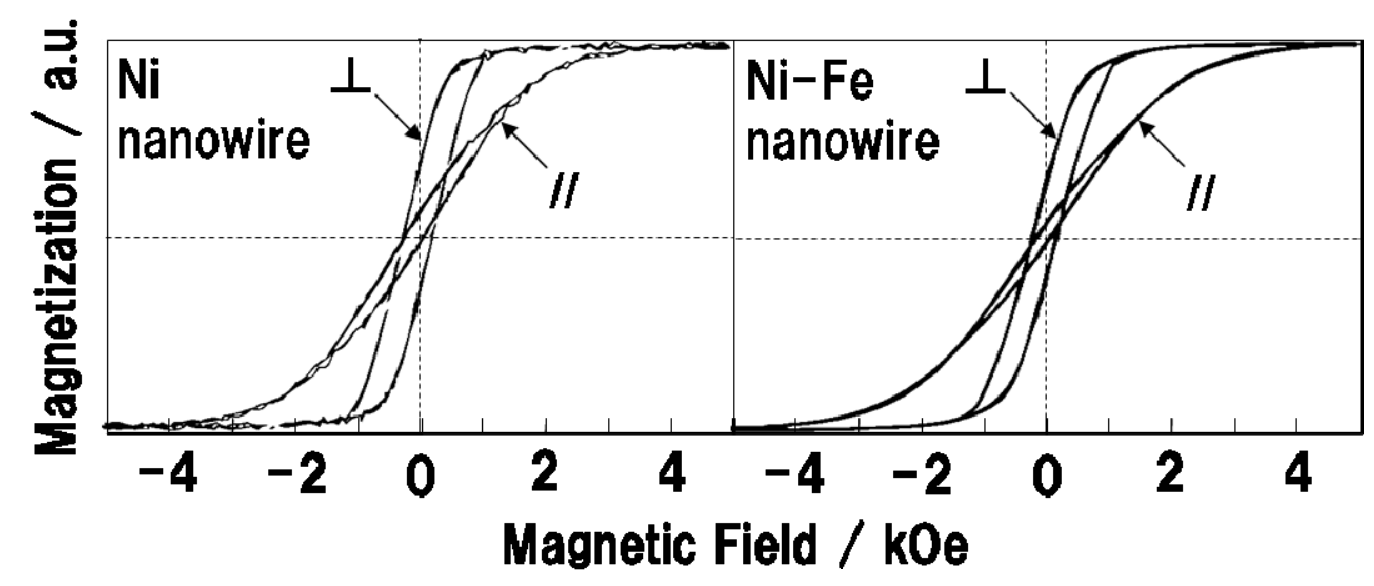


Figure 6 Magnetic hysteresis loops of $\mathrm{Ni}$ nanowires and $\mathrm{Ni}-22 \mathrm{at} . \% \mathrm{Fe}$ alloy nanowires electrodeposited from aqueous solutions.

\section{Conclusions}

The optimum deposition potential for electrodeposition of $\mathrm{Ni}$ and $\mathrm{Ni}$-Fe alloy is determined to be ca. $-1.0 \mathrm{~V}$. Fe ratio in deposit was condensed more than 10 times higher than $\mathrm{Fe}^{2+}$ ratio in bath. This phenomena was explained by the anomalous codeposition mechanism due to the formation and adhesion of $\mathrm{Fe}(\mathrm{OH})_{2}$ on cathode. Coercive force of Ni-22at.Fe alloy film was ca. $1 \mathrm{Oe}$, which is quite smaller than that of Ni film (ca. $110 \mathrm{Oe}$ ). Ni-Fe alloy films with low coercive force were obtained over the wide range of Fe content from $20 \%$ to $60 \%$. Growth rate of $\mathrm{Ni}$ and Ni-Fe alloy nanowires was ca. $6 \mathrm{~nm} \cdot \mathrm{sec}^{-1}$ at the cathode potential of $-1.0 \mathrm{~V}$. The cylindrical shape was precisely transferred from the nanochannels to the nanowires and the aspect ratio reached up to ca. 60 . The each nanowire was consisted of single crystalline domain. Basis on the uni-axial magnetic anisotropy and single magnetic domain structure of $\mathrm{Ni}$ and $\mathrm{Ni}-\mathrm{Fe}$ alloy nanowires, the magnetic hysteresis loops showed typical perpendicular magnetization behavior and the coercive force reached to around 200 Oe.

\section{Acknowledgements}

This work was supported in part by TDK Corporation, Mitutoyo Association for Science \& Technology, Yazaki Memorial Foundation for Science \& Technology, Research Foundation for Materials Science, Japan Society for the Promotion of Science (Grant-in-aid for Scientific Research C : No.19560734).

\section{References}

[1] C. R. Martin, Adv. Mater. 3, 457 (1991).

[2] T. M. Whitney, J. S. Jiang, P. C. Searson, and C. L. Chien, Science 261, 1316 (1993).

[3] I. Chlebny, B. Doudin, and J.-Ph. Ansermet, Nanostruct. Mater. 2, 637 (1993).

[4] C. R. Martin, Science 266, 1961 (1994).

[5] L. Piraux, J. M. George, J. F. Despres, C. Leroy, E. Ferain, R. Legras, K. Ounadjela, A. Fert, Appl. Phys. Lett. 65, 2484 (1994).

[6] A. Blondel, J. P. Meier, B. Doudin, and J.-Ph. Ansermet, Appl. Phys. Lett. 65, 3019 (1994).

[7] D. Aimawlawi, N. Coombs, and M. Moskovits, J. Appl. Phys. 70, 4421 (1991).

[8] K. Nielsch, F. Müller, A. P. Li, and U. Gösele, Adv. Mater. 12, 582 (2000).

[9] G. Sauer, G. Brehm, S. Schneider, K. Nielsch, R. B. Wehrspohn, J. Choi, H. Hofmeister, and U. Gösele, J. Appl. Phys. 91, 3243 (2002).

[10] T. Ohgai, X. Hoffer, L. Gravier, J. E. Wegrowe , J.-Ph. Ansermet, Nanotechnology 14, 978 (2003).

[11] T. Ohgai, X. Hoffer, A. Fabian, L. Gravier, J.-Ph. Ansermet, J. Mater. Chem. 13, 2530 (2003).

[12] T. Ohgai, L. Gravier, X. Hoffer, M. Lindeberg, K. Hjort, R. Spohr, J.-Ph. Ansermet, J. Phys. D: Appl. Phys. 36, 3109 (2003).

[13] K.E. Heusler, Zeit. Electrochimie 62, 582 (1958)

[14] J. O’M. Bockris and H. Kita, J. Electrochem. Soc. 108, 676 (1961).

[15] K. Higashi, H. Fukushima, T. Urakawa, T. Adaniya, K. Matsudo, J. Electrochem. Soc. 128, 2081 (1981). 